\title{
Specified Tests for Concrete Quality
}

\author{
Behnam Neyestani
}

\section{Introduction}

Concrete is unique among construction materials in that it requires various degrees of processing between arriving on site and being placed, compacted, finished and cured. This is true whether the concrete is site batched or arrives ready mixed. It is therefore necessary to sample the concrete and conduct concrete testing to ensure that it complies with the requirements of the project specification.

\section{Concrete Quality Control}

Tests for checking quality of concrete should be done for the following possible purposes:

1. To detect the variation of quality of concrete being supplied for a given specification;

2. To establish whether the concrete has attained a sufficient strength or concrete has set sufficiently for stripping, stressing, de-propping, opening to traffic, and;

3. To establish whether the concrete has gained sufficient strength for the intended purpose.

There are so many tests available for testing different qualities of concrete. Different tests give results for their respective quality of concrete. Thus it is not possible to conduct all the tests as it involves cost and time. Thus, it is very 
important to be sure about purpose of quality tests for concrete. The most important test for quality check of concrete is to detect the variation of concrete quality with the given specification and mix design during concrete mixing and placement. It will ensure that right quality of concrete is being placed at site and with checks for concrete placement in place, the quality of constructed concrete members will be as desired. However, the following are the lists of various tests conducted for concrete quality:

\section{A. Tests on hardened concrete:}

- Compressive strength (Cube);

- Tensile strength: Direct tension;

- Modulus of rupture;

- Density;

- Shrinkage;

- Creep;

- Absorption;

- Freeze/thaw resistance;

- Resistance to aggressive chemicals;

- Analysis for cement content and proportions, and;

Ultrasonic, nuclear.

\section{B. Tests on fresh concrete:}

- Workability Tests ( Slump Test and others)

- Bleeding; 
- Segregation resistance;

- Unit weight;

- Wet analysis;

- Temperature, and;

Heat generation.

Of these many tests for concrete quality, in practice well over $90 \%$ of all routine tests on concrete are concentrated on compression tests and slump tests. It is also desirable to conduct fresh concrete temperature and hardened concrete density determination tests. In practice the most commonly specified tests are the "slump test" and the "cube test". The reasons for the selection of "Cube Test" (Compressive Strength) and "Slump Test" (Workability Tests) in practice for quality control testing of concrete are:

1. All or most other properties of concrete are related to its compressive strength.

2. Compressive strength test is the easiest, most economical or most accurately determinable test.

3. Compressive strength testing is the best means available to determine the variability of concrete.

4. Slump tests also checks for variation of construction materials in mix, mainly water-cement ratio. 
5. Slump test is easy and fast to determine quality of concrete before placement based on recommended slump values for the type of construction.

6. Slump test is most economical because it is done at site and does not require any laboratory or expensive testing machine.

\section{Slump Test}

This test measures the consistence (wetness) of the concrete in the medium "workability" range. (Workability is a qualitative term describing the amount of work required to place and compact fresh concrete). The test is used to check that the water content of the concrete does not deviate significantly from the design value. The allowable deviation from the specified slump is plus or minus $25 \mathrm{~mm}$ or $1 / 3$ of the specified slump - whichever is the greater.

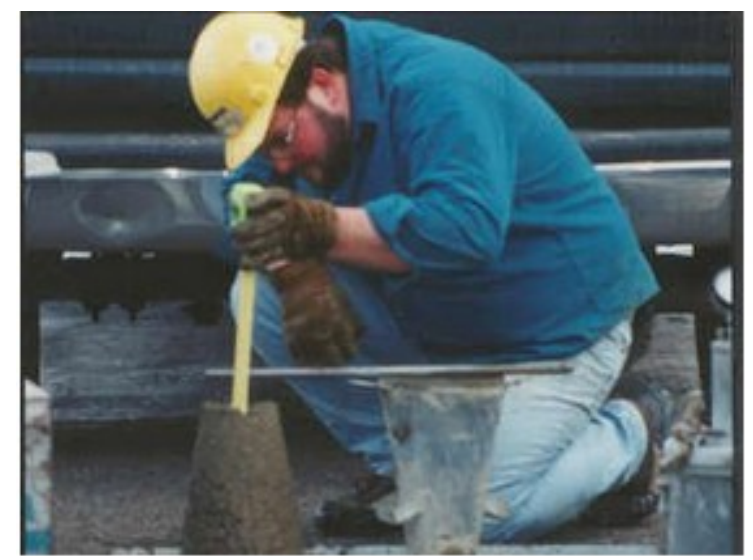

Figure 1: Slump test (Test concrete workability)

Large variability in slump test results, indicate one or more of:

- Poor control of amount of water added;

- Unacceptable variations in aggregate batching;

- Change in aggregate water requirement, and; 
- Poor testing procedure.

\section{Making and Curing of Test Specimens}

The three crucial factors in making and curing the specimens are:

- The condition of the cube moulds - Steel moulds are supplied in matched sets of pieces and the sides and bases from different moulds must not be mixed;

- The curing temperature - This should be between 22 and $25^{\circ} \mathrm{C}$.

It is important that the cubes are correctly labelled. Experience has shown the best method is to stick a paper label onto the top surface of the cube while the concrete is still plastic. The cube details are then written on the side of the cube with black lumber crayon when the cube is de-moulded. Scratching the cube number on the top surface of the fresh concrete is not recommended.

\section{Cube Test}

This test measures the uniaxial compressive strength of concrete cubes which are made, cured and tested to very specific requirements. It does not measure or predict in any unique way the strength of the concrete in the structure. The test is simply a quality control test which measures the consistency of the concrete in terms of one particular property ("compressive strength") using an arbitrary test method. Testing the same concrete under different conditions, for example specimen size, specimen shape, curing temperature, loading rate, etc. will give different results. From a quality control point of view, the importance of the cube 
test result is not just the value of any individual result, but the variability in a series of valid test results.

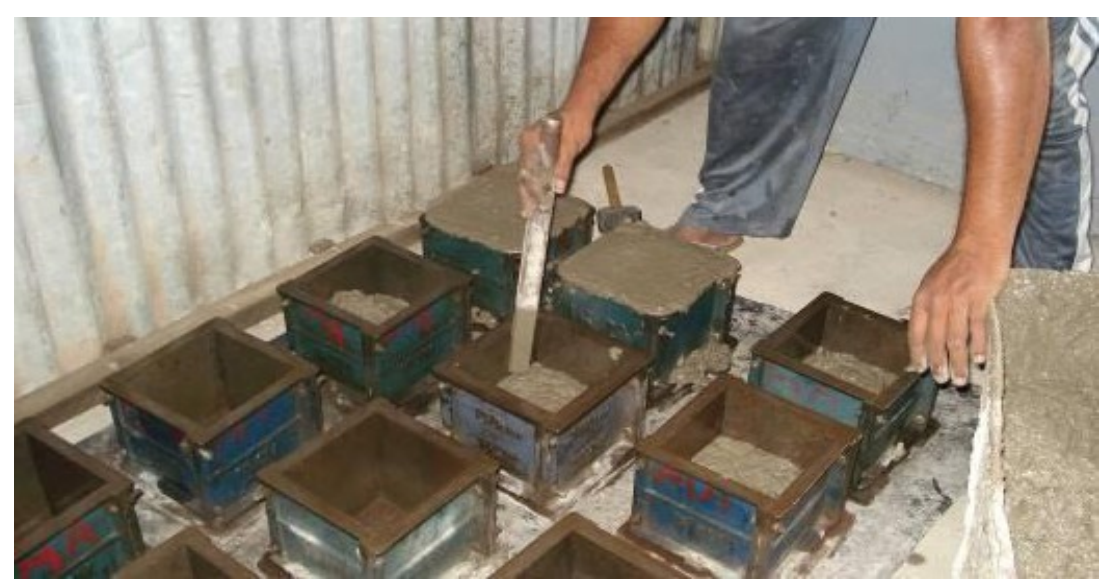

Figure 2: Concrete cubes for testing Error

\section{Valid Compressive Strength Test Result}

A valid test result is the mean of the results of tests carried out on three specimens which are sampled from the same batch of concrete, and which are made and cured under standard conditions at any particular age (for example, 3 or 7 or 28 days). This is with the condition that the range of strengths between the highest and lowest individual result does not exceed $15 \%$ of the mean. An invalid result, or a series of them, indicates one or more problems with the testing procedure. An invalid result is rejected from a quality control viewpoint and the cause of the invalidity must be investigated. Typical causes include poor sampling and cube making, mis-labelling of cubes, out of tolerance cube moulds, operator error, and malfunctioning compression machine.

\section{Compression Machine Reference Testing}

It is essential that compression test machines undergo regular reference testing at about 3 monthly intervals. The fact that a machine is calibrated does not imply 
that it is producing reliable results. The way to carry out reference testing is to make and cure a large batch of cubes and to circulate sets to participating laboratories for testing. The results are then compared. The testing is normally done at three different strength levels, but not necessarily all at the same time.

\section{Quality Control for Precast}

If you are going to manufacture precast products in your shop, you should consider doing your own quality control. Large precast operations have big labs and develop intricate quality procedures, testing all aspects of the concrete both before and after casting and developing extensive QC tools like fishbone charts and scatter diagrams and Pareto charts. You may not need to get to that level, but some basic testing and analysis can save you money both in production costs and higher quality precast products.

Starting with good materials is the first step. All aggregate is not acceptable for use in concrete. If there are organic materials, shale, chert, or other soft materials in your aggregate, you can't produce good concrete. Reactive aggregates can lead to alkali-silica reaction that can destroy your concrete. The best defense may be simply to require that the aggregate meets ASTM C 33, "Standard Specification for Concrete Aggregates." It's your aggregate supplier's responsibility to assure that you are getting good aggregate.

\section{Triparish Testing and Inspection}

Sampling the fresh concrete is critical and the simplest test is slump. Although not always the best measure, slump does indicate workability, which Adam Neville, in his book "Properties of Concrete," defines as "the amount of useful internal work 
necessary to produce full compaction." Slump can vary dramatically, though, when admixtures are used. The best use for slump is to give you some indication of whether the mix will flow easily into the forms and to monitor different batches of the same mix design. All else equal, different slumps indicate different amounts of water, but slump variations can also indicate changes in entrained air content, aggregate moisture, or temperature. The temperature of the concrete is another important thing to test. Cold concrete can set very slowly and will mean waiting longer to strip the molds. Hot concrete gains strength faster, but the ultimate strength will be lower. Higher temperatures can also reduce air entrainment and workability. Hot concrete can lead to cracks as thermal gradients develop.

\section{REFERENCES}

Day, K. (2003). Concrete Mix Design, Quality Control and Specification. CRC Press.

Gibbs, J. C., \& Zhu, W. (1999, September). Strength of hardened self-compacting concrete. In Proceedings of First international RILEM Symposium on SelfCompacting Concrete (PRO 7), Stockholm, Suede, pp. 199-209.

Ho, D. W. S., \& Lewis, R. K. (1987). Carbonation of concrete and its prediction. Cement and Concrete Research, 17(3), 489-504.

Komlos, K., Popovics, S., Nürnbergerová, T., Babal, B., \& Popovics, J. S. (1996). Ultrasonic pulse velocity test of concrete properties as specified in various standards. Cement and Concrete Composites, 18(5), pp. 357-364.

Neville, A. M. (1995). Properties of concrete (Fifth Edition). Tottenham Court Road. London: Pearson Education Limited. (ISBN: 978-0-273-75580-7)

Sri, R., \& Tam, C. T. (1985). Properties of concrete made with crushed concrete as coarse aggregate. Magazine of Concrete Research, 37(130), pp. 34-49.

Stanish, K. D., Hooton, R. D., \& Thomas, M. D. A. (2000). Testing the chloride penetration resistance of concrete: a literature review. Toronto, Ontario, Canada: Department of Civil Engineering, University of Toronto.

Tattersall, G. H. (2003). Workability and quality control of concrete. CRC Press. 